\title{
Role of Social Media In Reducing Culture Shock: A Research of Interstate Migrants in Jammu
}

\author{
Annie Jamwal, Pragya Khanna
}

\begin{abstract}
In the era of globalisation, migration has become a common phenomenon in India. The interplay between push and pull factors play an important role in both internal and external migration. However, it is pertinent to mention that when individuals migrate it is not only the migration of a physical being but the migration of cultures as well. These migrating cultures undergo various changes in their forms as the result of culture contact. This may be in form of assimilation or acculturation. But at the same time one of the major impacts on the migrating individual can be seen in form of culture shock which is generally a feeling of disorientation experienced by the migrating individual who is subjected to unfamiliar culture. Here comes the role of various institutions and mediums that facilitate the process of cultural adaptation. The growth of social media has helped in bridging the gap between distinct societies by connecting like-minded individuals. It helps to gain a prior knowledge regarding the customs, traditions, beliefs of host cultures along with maintaining strong ties with the families and friends which reduces the threshold of migration. This paper attempts to analyse the role of social media in reducing culture shock while studying interstate migrants in Jammu, J\&K by opting in-depth interviews using qualitative method. Depending upon the analysis, discussions are stated that social media plays an important role in facilitating intercultural adjustments.
\end{abstract}

Index terms: Culture, Cultural adaptation, Culture shock, Interstate migrants and Social media.

\section{INTRODUCTION}

"Migration is an expression of the human aspiration for dignity, safety and a better future. It is part of the social fabric, part of our very make-up as a human family". (Ban Ki-moon, Secretary-General (2007-2016), United Nations, at the 2013 High-level Dialogue on International Migration and Development)

$\mathrm{Be}$ it internal or external migration, the migrating individual is always subjected to new socio-cultural environment as the result of moving to new geographical area. Migration has shown an upward trend in recent times for various reasons including push and pull factors for migration. Managing the human mobility is tough in both forced as well as voluntary migration. The migrating individuals come across a variety of new customs, traditions, beliefs and practices of host cultures. This can lead to psychological stress or depression or disorientation in adapting to new unfamiliar cultures which can be termed as culture shock. There are various institutions and mediums that can help in cultural adaptations. In present day digitalised world, social media comes into picture when one thinks of making intercultural adjustments.

Revised Manuscript Received on December 30, 2019.

Dr. Annie Jamwal, BAMS, Masters in Anthropology (Email: annie.jamwal@gmail.com)

Dr. Pragya Khanna, PhD, D.Litt., MNASc., FSLSc., FIASc., FESW (Email: pragyajmu2002@yahoo.com)
Social media is a communication mechanism that allow users to communicate with thousands, and perhaps billions, of individuals all over the world (Williams et al., 2012).

Social media has enhanced connectivity across time and space. It helps in building virtual ties and be the part of social life as never before. In recent times, social media has emerged as key factor in building intercultural ties. It helps the migrants to have a prior knowledge of traditions and belief host cultures which creates a sense of affinity without being part of that culture. Thus, it helps in connecting the far distinct societies across the world which has finally led to emergence of shrunken world (Sawyer and Chen, 2012).

Social media also helps in maintaining a regular contact within families and friends which further lowers down depression from the physical separation (Chruch, 1982).Therefore social media is a medium of bridging social gaps and bringing stabilisation between the new and old relations. Migrating individuals who are new to the host cultures use mediums to resist and assist the intercultural adaptations (Croucher, 2011).

Now a days many research works have been taken up to analyse the role of social media in reducing culture shock. With the emergence of missions like "Digital India" social media has reached to every nook and corner of country but still in sensitive regions like Jammu and Kashmir where snapping of internet is frequent due to security reasons, the interstate migrants generally come across the challenging situations while trying to adapt with local culture as their connection with their families is generally disrupted. This study focuses on cultural adjustments among interstate migrants and facilitating role played by social media in this process. This study analyses the stabilisation role played by social media in the process of cultural adaptation.

\section{THEORETICAL BACKGROUND}

Theory of diffusion of cultures:

The theory of diffusion also interprets the cultural evolution in terms of "cultural similarities", "mutual contact", "cultural cradle "and "cultural area". According to theory of diffusion culture traits may also get transferred by migrating individuals into the new area where they move temporarily or on permanent basis and may communicate their culture to local people along with getting exposed to new elements of host culture. Thus, diffusionists believe that cultures grow in course of history, not because of evolution only but also due to culture contact. (Makhan Jha, 2004) 
Graebner also opined that as travel became easy, the influence of culture centres began to radiate, more or less, in the aggregate form. Graebner conceded that some Polynesian traits may have been imported from America.

Culture shock and its causes

The term culture shock was first mentioned by Kalvero Oberg in 1960.It is also known as "culture adjustment stress". Culture shock can be referred as a condition arising out of migration of people from a familiar culture to an unfamiliar culture resulting in distress or disorientation or a feeling of discomfort as the result of culture contact. Culture shock is common phenomena in students, tourists, employees or persons involved in any other work that requires frequent migration. Culture shock requires immediate attention as it can lead to serious consequences. A person experiencing culture shock moves through four stages: Honeymoon stage, frustration stage, adjustment stage and adaptation stage.

Stages of Culture shock:

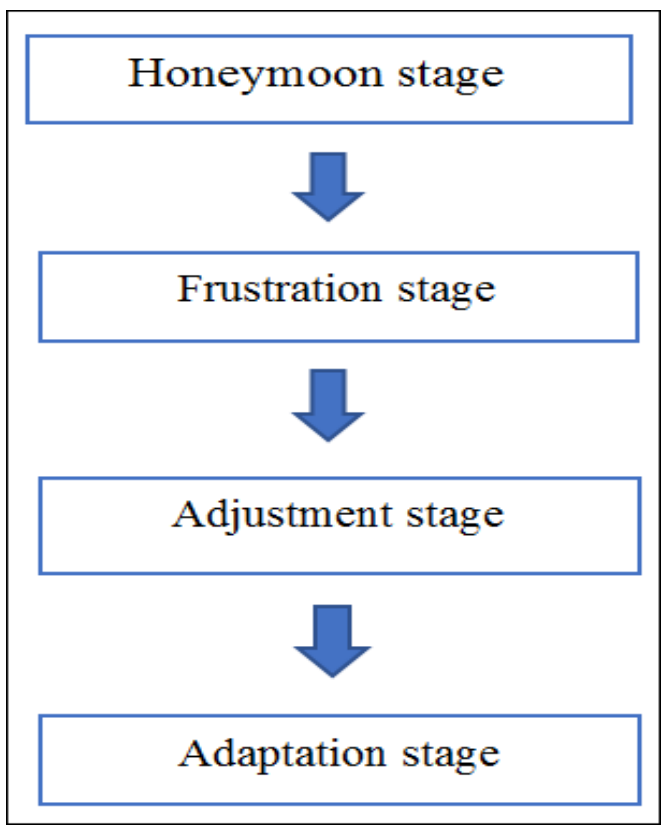

Honeymoon stage is characterised by extremely positive, euphoric and excited feelings. Frustration stage is the one in which excitement turns into discomfort and this leads to impatience and anger. Adjustment stage involves a sense of little comfort arises and person stats feeling better and a feeling referred as "home like comfort" comes. Adaptation stage is the stage of acceptance and contributes to integration finally.

Causes of culture shock involve mismatch in the expectations, newness of the cultural environment (which may be in form of backwardness or forwardness) and changes in education system (if target group is a student). Persons undergoing culture shock may feel homesick, lonely, weak or even inferior from the local people. He/she may appear stressed, shy or introvert.

Role of social media in cultural adjustment:

Gudykunst (2003) mentioned the adaptation as a "dynamic process by which individuals, upon relocating to an unfamiliar cultural environment, establish or re-establish and maintain a relatively stable, reciprocal and functional relationship with the environment." This process of cultural adaptation is facilitated by mediums like social media that has enhanced connectivity all across the globe. It comes into the picture during the last stage of culture shock i.e. adaptation (also known as biculturism) in which persons adjust with the host culture and try to adapt it.

As per Elola and Oskoz(2009), social media use enhances intercultural relationships by improving communication between the people belonging to two different cultures. Social media becomes the platform for building personal network and hence helps in multicultural interactions. According to Sawyer and Chen(2012), in American migrants cultural adaptation became easy through the use of social media.

\section{METHODOLOGY}

For analysing the role of social media in reducing culture shock among interstate migrants in Jammu, the researcher made in-depth interviews of 120 interstate migrants who belonged to different sections of society including students, employees and businessmen. In order to get precise data, the approach based on qualitative research method was used and investigations were done after detailed discussions. The participants were mostly temporary residents in Jammu. As per the answers of the participants it can be found that some of the participants used social media to connect to host cultures. However, the use of social media is largely confined to literate population. The interview was designed to analyse how social media helps in intercultural communication and establishing relations with new community.

\section{DATA COLLECTION}

Researcher collected data by making in depth interviews of people belonging to different age groups and different sections of society. All the participants are currently residing in Jammu at least from last six months. Data regarding their own culture was also collected in this process. The researcher also tried to figure out questions that can help to analyse the role of social media in reducing culture shock thereby facilitating cultural adjustments.

\section{DATA ANALYSIS}

The focus of the questionnaire was on two sections:

1) Analysing the kind of culture shock in different sections of society.

2) Role of social media in different stages of culture shock particularly the adjustment and adaptation stage.

\section{ROLE OF SOCIAL MEDIA IN REDUCING CULTURE SHOCK\& RESULTS}

Culture shock is an interesting subject of study for it having different meanings and different experiences for different people. A wide variation is seen regarding the perceptions of different people to different cultures. People migrating from different parts try different ways to adapt to different cultural environments. 
The answers of participants regarding the culture shock they faced upon coming to extreme northern part of country i.e. Jammu could highlight their first-hand experiences as well as their response to strange cultural elements of host culture. However, researcher tried to focus particularly on role of social media in cultural adaptation process.

Some of the strange elements of culture of Jammu experienced by interstate migrants from different parts of country that acted as barriers in cultural adaptation are as reported below:

\section{Types Of Barriers in Cultural Adaption}

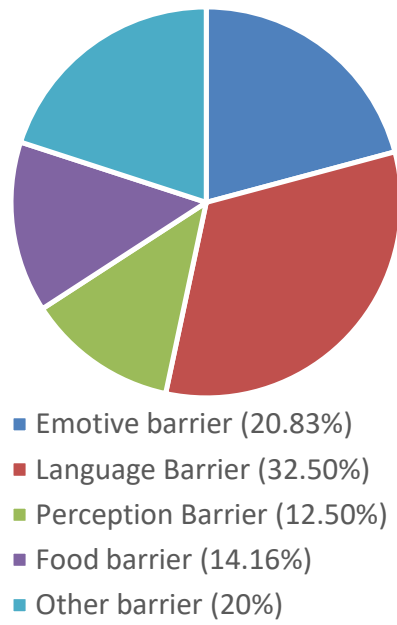

\section{Linguistic barriers:}

Most the participants reported problem in communication as mostly the people from south India faced difficulty in communicating in Hindi language and the local people can communicate mostly in Hindi or Dogri (local language) while some of them can understand and speak English. This made the interaction with local people almost impossible which resulted in gap between the local communities and migrant individuals.

\section{Food barriers:}

Respondents felt that migrating from places like down south, eastern India or western India having their own elaborate food culture makes difficult to adapt to wheat eating culture. Thus, food becomes one of the factors in increasing home sickness. This kind of problem was mainly faced by people from areas which are generally not in culture contact with north India.

\section{Emotive barriers:}

One of a major reason regarding the inability to adapt to host culture is absence of family and friends in new place. People generally try to connect to their families when they face adjustment problems. Distance from dear ones is generally one of main reasons of feeling depressed as everything around is unfamiliar.

\section{Perception barriers.}

Respondents encountered various preconceived notions regarding their ethnicity and cultures. This was mainly seen in case of people belonging from north east part, when people relate them with Nepalese or Chinese people.

These barriers delayed the process of cultural adaptation in general. However, the respondents used social media mainly in two ways to overcome these barriers and reduce culture shock. Firstly, in communicating with local people in order to adapt to host culture and secondly in maintaining ties with homeland (family and friends) to reduce the threshold of migration.

\section{CONCLUSION}

This paper analyses that how social media helps in reducing culture shock and bridging the gaps between host culture and parent culture. Throughout the study it was observed that whatever be the nature of migration (temporary or permanent), section of people migrating (students, workers, employees, tourists), the area from where they are migrating or the culture they had in their homeland, all people face the problem of culture shock at one point of time.

The kind of culture shock varies from person to person. For some it might be in form of language problem, food problem or customs they follow while for some it may be a wholistic one. Moreover, it was also observed that all kinds of migrants try to adapt to new culture but the pace of adjustment varies from person to person. Some people have shorter frustration stage and longer adaptation phase and vice versa. Adaptation to new cultural elements requires the support of various institutions and agencies. Cultural adaptation is a two-way process i.e. adapting the culture of new community and at the same time maintaining ties with one's own community.

Social media plays an important role in order to help a person who has left his own land and migrated to a place where he has never been before. During the study it was observed that use of social media is not limited to a particular age group. People from all age groups are comfortable using social media to connect to people belonging to their own area of interest. However, target group varies from person to person. Respondents said that they use social media to connect to local people so that they can have a better insight regarding local Dogra culture Thus, the research also highlights that social media play as one of the best methods for interaction and conversation for interstate migrants to keep in touch with their home lands and learn about intercultural practices and experiences.

The respondents also mentioned that social media helped them to clear the misconceptions regarding the local culture and having better knowledge about the customs and traditions. However ,it was established that social media helped in reducing culture shock in three major ways: Firstly it helped the migrants to connect with the local community their by easing their journey of adapting host culture, secondly it helped them to connect to their homeland frequently so that they can share their problems with their dear ones thereby reducing frustration and stress and thirdly it helped them to look for various avenues of employment so that they can earn their livelihood while engaging with local people which also enhanced their contact with the local culture. But at the same time study also concluded that not all the interstate migrants were using social media (particularly those belonging to labourers' class who are involved in seasonal migration). 
People belonging to this class are also well adapted to local culture and are mostly successful in finding jobs they prefer in new culture also. In this case the process of cultural adaptation can be attributed to factors other than social media.

\section{FUTURE AREAS OF RESEARCH}

There are some facts in this research which are limited. The first thing is that the researcher analysed only the role of social media but there are lot many factors that facilitate cultural adaptation. Hence, it is strongly suggested that analysis of some other factors that facilitate cultural adjustments would give a more comprehensive picture about the process of cultural adaptation in diverse communities. Moreover, comparisons within different age groups will also give a different perspective to research in order to analyse that whether cultural adaptations are age specific phenomena i.e. more in younger population than older or vice versa. This will analyse that whether age plays any role in helping a person to adjust to any kind of environment. On the same lines research can be conducted to analyse cultural adaptation capabilities within literate and illiterate sections of society. This will analyse the role of education in facilitating cultural adaptation and reducing culture shock.

The analysis can also be carried about the impact of host culture on parent culture. Whether the culture contact led to processes like assimilation, acculturation, enculturation or simple adoption.

\section{CONFLICT OF INTEREST}

The authors declare no conflicts of interest regarding the publication of this paper.

\section{REFERENCES}

1. Church, A. T. (1982). Sojourner Adjustment. Psychological Bulletin, 91, 540. https://doi.org/10.1037/0033-2909.91.3.540 [Paper reference $1]$.

2. Croucher, S. M. (2011). Social Networking and Cultural Adaptation: A Theoretical Model. Journal of International and Intercultural Communication, 4 259-264. https://doi.org/10.1080/17513057.2011.598046 [Paper reference 1].

3. Elola, I., \& Oskoz, A. (2009). Blogging: Fostering Intercultural Competence Development in Foreign Language and Study Abroad Contexts. Foreign Language Annals, 41, 454-477. https://doi.org/10.1111/j.19449720.2008.tb03307.x [Paper reference $1]$.

4. Gudykunst, W. B. (2003). Cross-Cultural and Intercultural Communication. Thousand Oaks, CA: Sage Publications, Inc. [Paper reference 1]

5. Sawyer, R., \& Chen, G. M. (2012). The Impact of Social Media on Intercultural Adaptation. [Paper reference 4].

6. Williams, D.L., Crittenden, V.L., Keo, T. and McCarty, P. (2012), "The use of social media: an exploratory study of uses among digital natives", Journal of Public Affairs, Vol. 12 No. 2, pp. 127-136.

7. Makhan, Jha. (1994). "An introduction to anthropological Thought", Vikas Publishing House PVT. 